
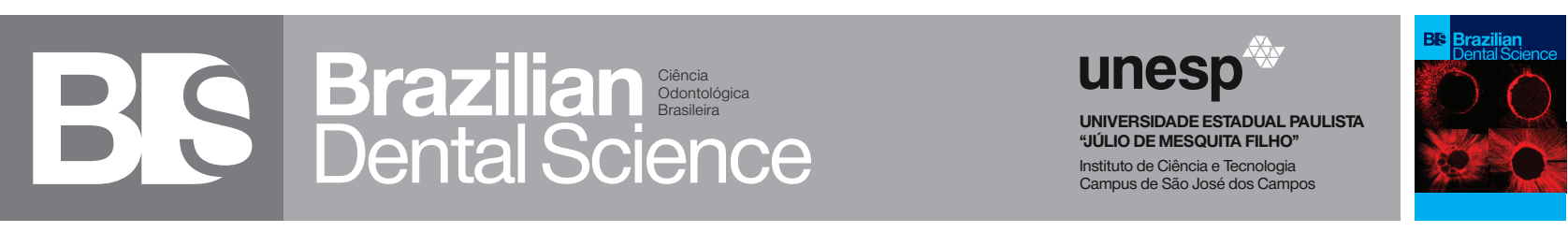

\title{
Repair Protocol of Porcelain Laminate Veneers Through Reattachment of the Fractured Ceramic Piece: A Technical Report
}

Protocolo de reparo de laminados de porcelana através de recolocação da peça de cerâmica fraturada: um relato técnico Elif DULUNDU ${ }^{1}$, Halenur BILIR ${ }^{2}$, Duygu KARAOSMANOĞLU' ${ }^{1}$, Mutlu ÖZCAN ${ }^{3}$

1 - Creadenta Private Dental Clinic - Istanbul - Turkey.

2 - Istanbul Medeniyet University - Faculty of Dentistry - Department of Prosthodontics - Istanbul - Turkey.

3 - University of Zürich - Dental Materials Unit - Center for Dental and Oral Medicine - Clinic for Fixed and Removable Prosthodontics and Dental Materials Science - Zürich - Switzerland.

\begin{abstract}
This technical report has been developed to repair the ceramic laminate veneer without removing after fracture. The bonding between the tooth and the laminate veneer is very strict, thus removing the restoration is difficult. The disadvantages such as the loss of tissue from the tooth, the cost and time loss are eliminated with this technique. In this technical report, the cementation of porcelain to porcelain in the presence of the fractured piece is explained step by step.
\end{abstract}

\section{KEYWORDS}

Ceramic; Laminate veneers; Repair.

\section{RESUMO}

Este relato técnico foi desenvolvido para reparar o laminado cerâmico sem remoção após fratura. A união entre o dente e o laminado é muito rígida, remover a restauração é difícil. As desvantagens como a perda de tecido do dente, o custo e a perda de tempo são eliminadas com esta técnica. Neste relato técnico, a cimentação de porcelana em porcelana na presença da peça fraturada é explicada passo a passo.

\section{PALAVRAS-CHAVE}

Cerâmica; Laminados; Reparo.

\section{INTRODUCTION}

eramic laminate veneers have become an important restorative procedure for the treatment of especially anterior teeth because of their biocompatibility, satisfying expectations about esthetics and long-term success in the clinic [1] .Despite the long-term success of ceramic laminate veneers, when clinical followup studies were investigated, there are some mechanical failures (debonding, chipping and fracture) [2-4].

Clinicians have to know the mechanical properties of the materials, because of choosing the correct materials and encountering lower rate of failure. Flexural strength and fracture toughness are important mechanical properties for fracture of glass-ceramic materials. Flexural strength measured the strength of the brittle materials and fracture toughness measured the fracture resistance of brittle materials [57]. When investigating suitable materials for laminate veneers, there are two materials mainly: feldspathic porcelain and lithium disilicate based ceramics $[8,9]$. Flexural strength and fracture toughness of leucite reinforced ceramics are lower than lithium disilicate based ceramics $[9,10]$. 
Although the mechanical properties that mentioned above are good for lithium disilicate based ceramics, in some cases fractures can be observed. Several clinical and laboratory factors may also contribute to such failures alone or in combination. Clinical factors include improper occlusal adjustment, lack of ceramic polishing after occlusal adjustments and parafunctional habits. Laboratory processing steps are also related these mechanical failures [11] .

In this technical report, repairing protocol of lithium disilicate reinforced ceramic laminate veneer which has cohesive fractured piece is described. The fractured ceramic piece is bonded to lithium disilicate ceramic surface.

\section{TECHNIQUE}

A 35-year-old male patient was applied to the clinic with a fracture on the mesial incisal edge of lithium disilicate crown restoration in tooth number 11 . The patient also brought the entire fractured piece. It was decided to cement the entire fractured piece to the restoration with adhesive system instead of replacing this restoration.

1. If there is a sharp pointed places in the fractured area in the ceramic surface

(Figure 1), smooth these places with diamond bur with low speed handpiece.

2. Check the presence of any contact at the level of the fracture line with the articulating paper (Bausch Articulating Paper, Dr. Jean Bausch GmbH \& Co. KG) (Figure 2).

3. Apply 4\% hydrofluoric acid (Porcelain Etchant, Bisco) for 1 min to fractured piece of the laminate veneer (Figure 3). Then wash for 1 min and dry with oil free compressed air.

4. Apply silane coupling agent (Monobond $S$, Ivoclar Vivadent) to fractured piece of laminate veneer and allowed to react $1 \mathrm{~min}$ (Figure 4).

5. Apply a thin layer of light curing bonding agent (Heliobond, Ivoclar Vivadent) to fractured piece of laminate veneer (Figure 5).
Remove any excess with compressed air.

6. Isolate the teeth with rubberdam (Roeko Dental Dam, Coltene). Also cover right upper lateral incisor and left upper central incisor with polytetrafluoroethylene tape (Figure 6).

7. Clean the fractured area in the tooth with polishing paste and brush.

8. Apply 4\% hydrofluoric acid (Porcelain Etchant, Bisco) for $1 \mathrm{~min}$ to fractured area in the tooth (Figure 7). Then wash for $1 \mathrm{~min}$ and dry with oil free compressed air.

9. Apply silane coupling agent (Monobond $\mathrm{S}$, Ivoclar Vivadent) to fractured area on the teeth and allowed to react $1 \mathrm{~min}$ (Figure 8).

10. Apply a thin layer of light curing bonding agent (Heliobond, Ivoclar Vivadent) to the entire surface area which needs to be repaired. Remove any excess with compressed air (Figure 9).

11. Apply resin cement (Variolink N LC, Ivoclar Vivadent) to fractured piece of laminate veneer inner surface (Figure 10).

12. After placement of the piece of laminate veneer, apply to light (Bluephase, Ivoclar Vivadent) labial surface of the laminate veneer for $40 \mathrm{~s}$ (Figure 11). The light have to be at least $800 \mathrm{~mW} / \mathrm{cm} 2$.

13. For oxygen inhibitation layer, apply glycerine gel (Ivoclar Vivadent Liquid Strip Glyceringel) to border of the fracture and during 40s apply the light from buccal, palatinal and marginal side.

14. After rinse the glycerine gel, remove excess cement with low speed handpiece and finishing burs under water.

15. Polish fractured line with silicone polishers (EVE Diapol Twist, Ernst Vetter GmbH) under water (Figure 12). If you need you can use interproximal polishing strip.

16. At the end, check the contacts in centric occlusion, lateral and protrusive movements of the jaw (Figure 13). 


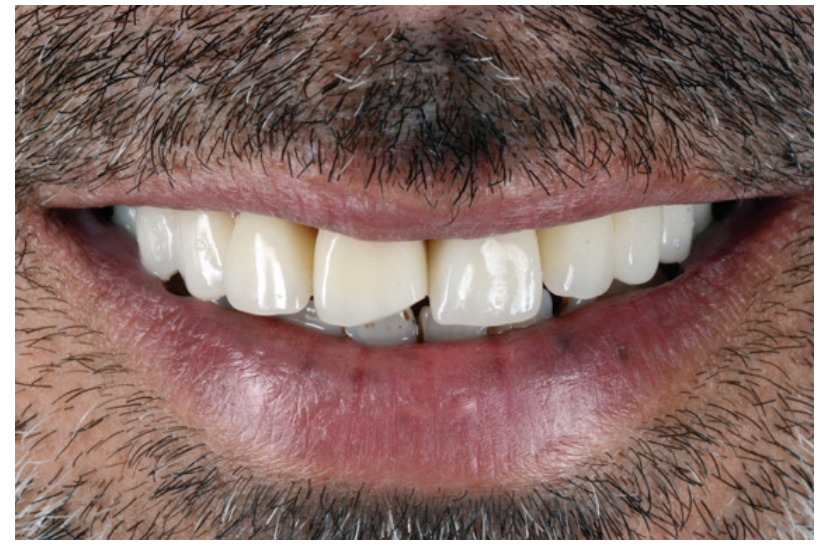

Figure 1 - Frontal view of porcelain laminate veneer fracture.

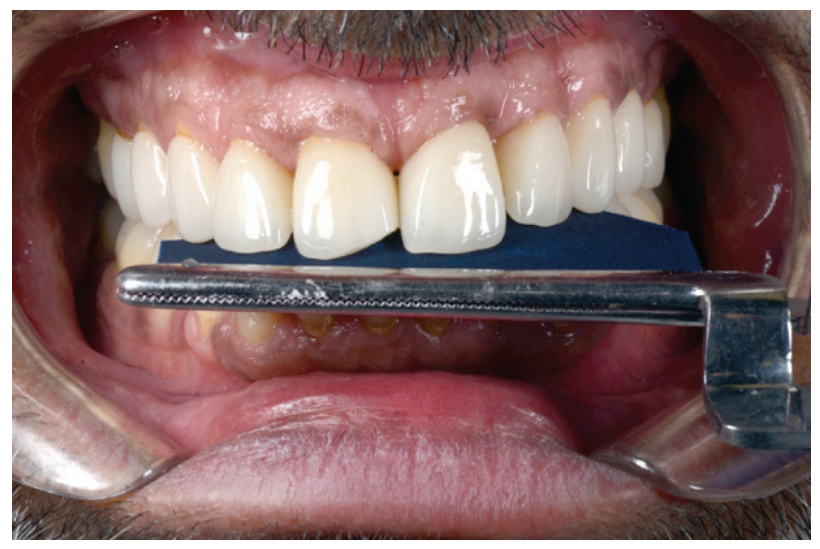

Figure 2 - Occlusion control for presence of any premature contact at the level of the fracture line with articulating paper.

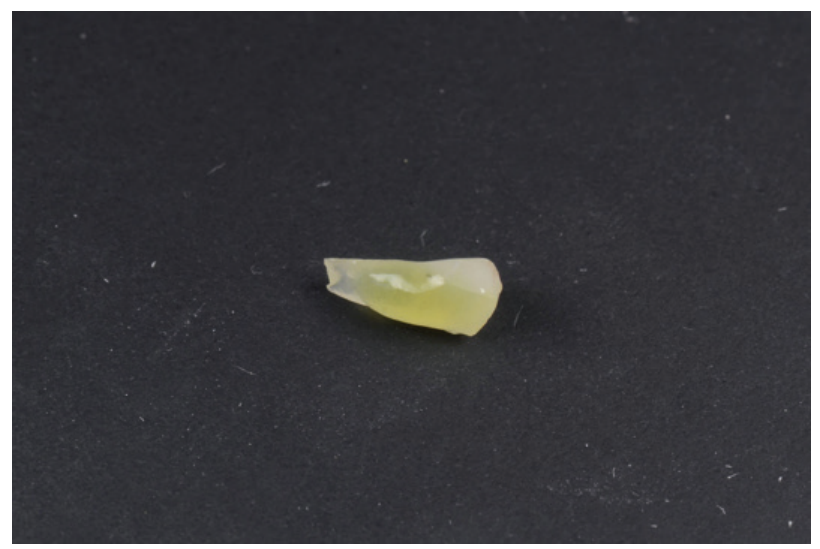

Figure 3 - Etching fractured piece of porcelain laminate veneer with $4 \%$ hydrofluoric acid for $1 \mathrm{~min}$.

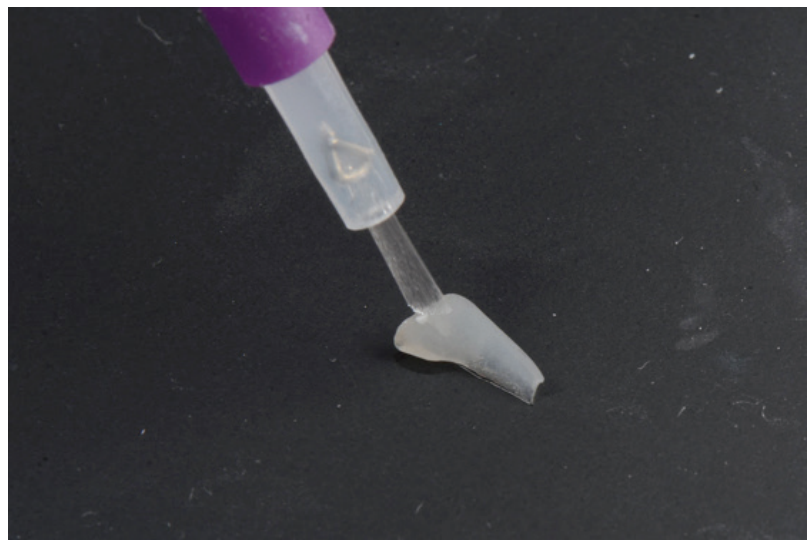

Figure 4 - Application of silane coupling agent and waiting for its reaction for $1 \mathrm{~min}$.

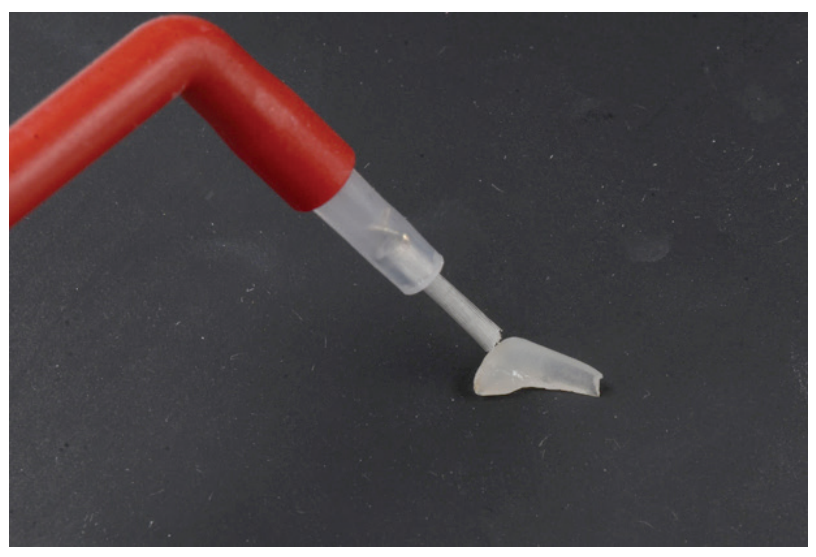

Figure 5 - Application of light curing bonding agent.

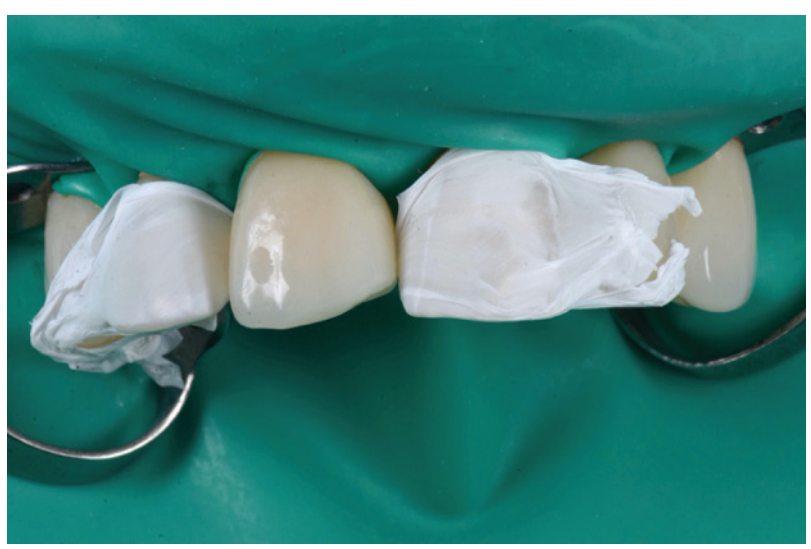

Figure 6 - Isolation with rubberdam and polytetrafluoroethylene tape. 


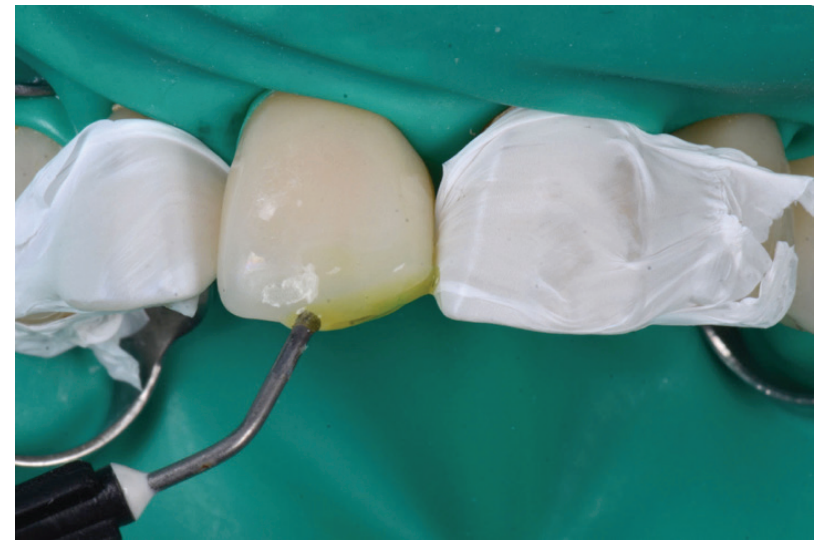

Figure 7 - Fractured ceramic area etching with $4 \%$ hydrofluoric acid for $1 \mathrm{~min}$.

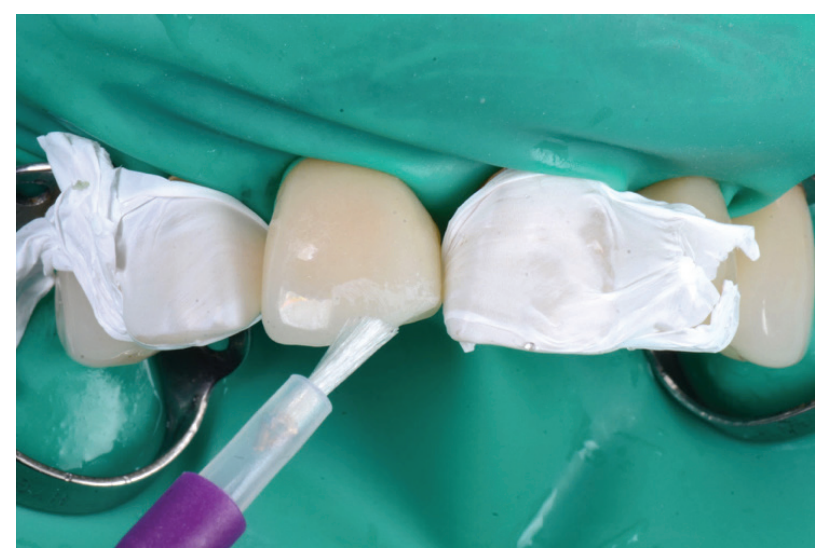

Figure 8 - Application of silane coupling agent and waiting for its reaction for $1 \mathrm{~min}$.

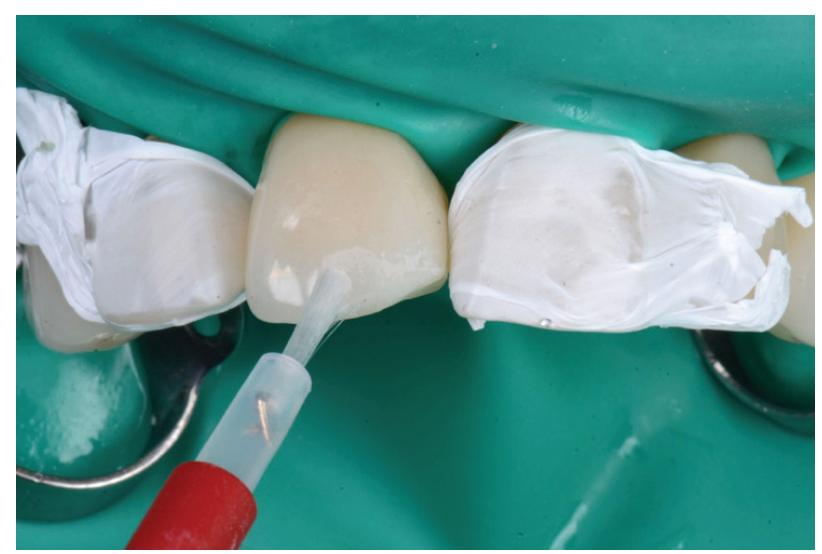

Figure 9 - Application of light curing bonding agent.

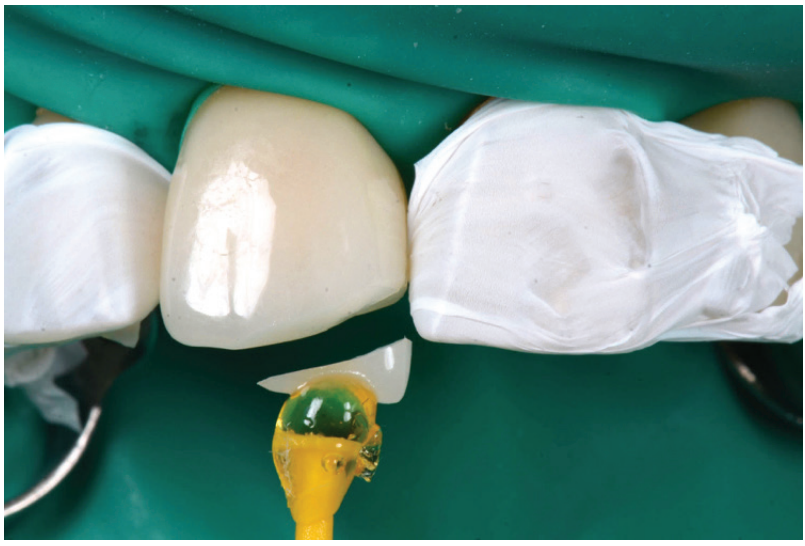

Figure 10 - Bonding the fractured piece of porcelain laminate veneer to ceramic area on the teeth.

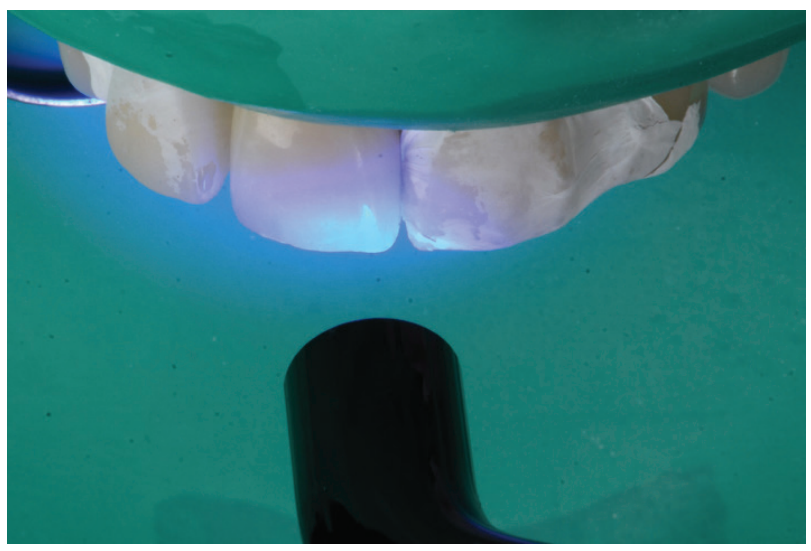

Figure 11 - Photo-polymerization of the light-cure adhesive resin cement.

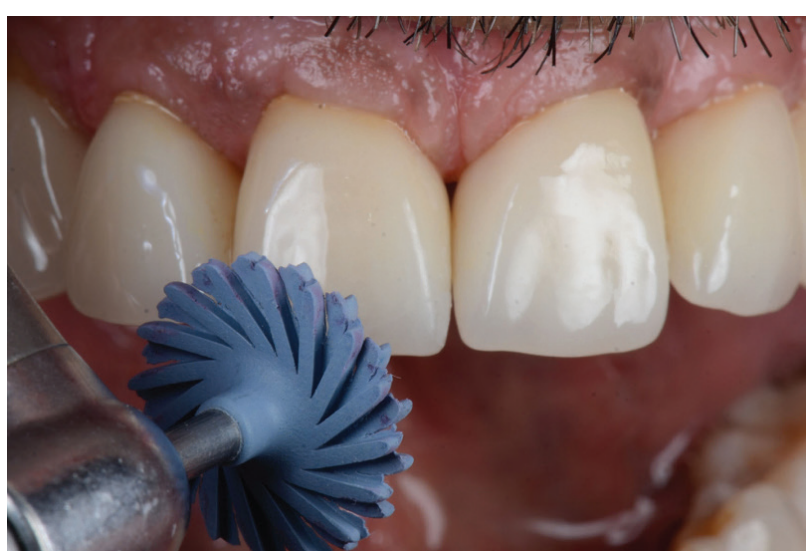

Figure 12 - Finishing and polishing of the porcelain laminate veneer. 


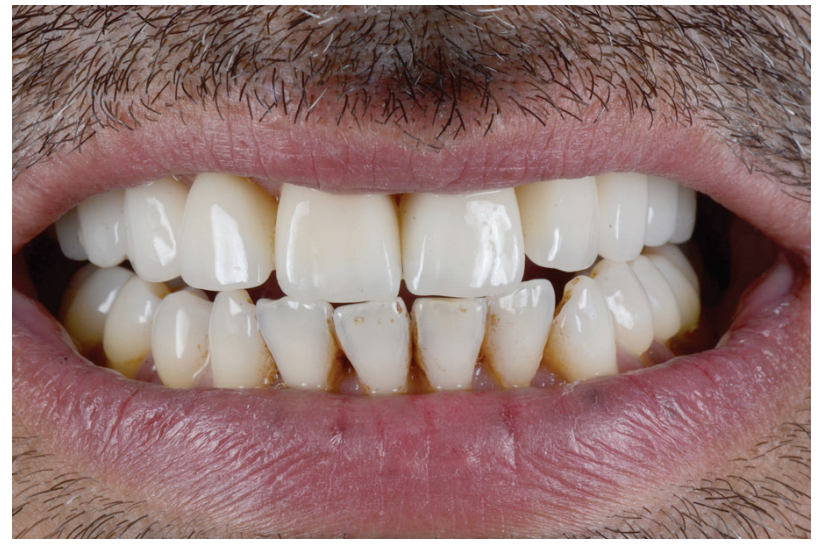

Figure 13 - Occlusion control during anterior movement.

\section{DISCUSSION}

Laminate veneers are restorations that can be safely used by patients for many years. In meta-analysis of Morimoto et al. [3] , cumulative survival rate of feldspathic porcelain laminate veneers is $87 \%$ and cumulative survival rate of glass ceramic laminate veneers is $94 \%$, the median of maximum follow-up times are 8 years and 7 years respectively. Although this restorations are successful clinically, some types of failures like debonding, chipping/ fracture, marginal or total discoloration, hypersensitivity, secondary caries, periodontal problems and endodontic problems are observed. It is thought that debonding failures will be more common than the other failures because of non retantive feature of laminate veneers. But chipping and fracture related failures are more common than the others. These situation is confirmed by long term clinical follow-up studies of Gürel et al.(debonding rate: $2 \%$, chipping/fracture rate: 3\%) [12] , Beier et al. (debonding rate: 1\%, chipping/fracture rate: 5\%) [13], Freadeni et al. (debonding rate: $2 \%$, chipping/fracture rate: 3\%) [14] , Gresnigt et al. (debonding rate: 1\%, chipping/fracture rate: 4\%) [15], Smales et al. (debonding rate: $2 \%$, chipping/fracture rate: 5\%) [16] and Rinke et al. (debonding rate: $2 \%$, chipping/fracture rate: $3 \%$ ) [17] .

The procedures that can be performed in case of clinical failures were defined by Setcos et al.[18] under four different headings and then these definitions were redefined by FDI criteria [19]. These are no treatment (monitoring), refurbishment, repair and replacement. Also treatment recommendations for chipped ceramic restorations are published by Heintze and Rousson [20] . Small chippings are grade 1 and can be trated with polishing. Moderate chippings are grade 2 and can be repaired with composite resin. Severe chippings are grade 3 and treatment option is replacement of entire restoration.

Repairing or replacing are choice for clinicians in small chipping/fracture failures of laminate veneers. The complete replacement of a restoration is both time consuming and expensive. Also tooth structure could be damaged during replacement or additional preperation. Unacceptable restorations can be replacing, but recently repairing has also been recommended as a current treatment option $[21,22]$.

In the previous technique, fractured parts were repaired with composite restorations [22] . Discoloration and compatibility with porcelain surface are disadvantages of repairing with composite. The advantage of this technique is the repair of a lamina veneer with own piece. It seems extremely one-piece, because it is cemented with its own part (Figure 14-18)

In present case, which was repaired with its own part, no failure was observed during 3 years clinical follow-up.

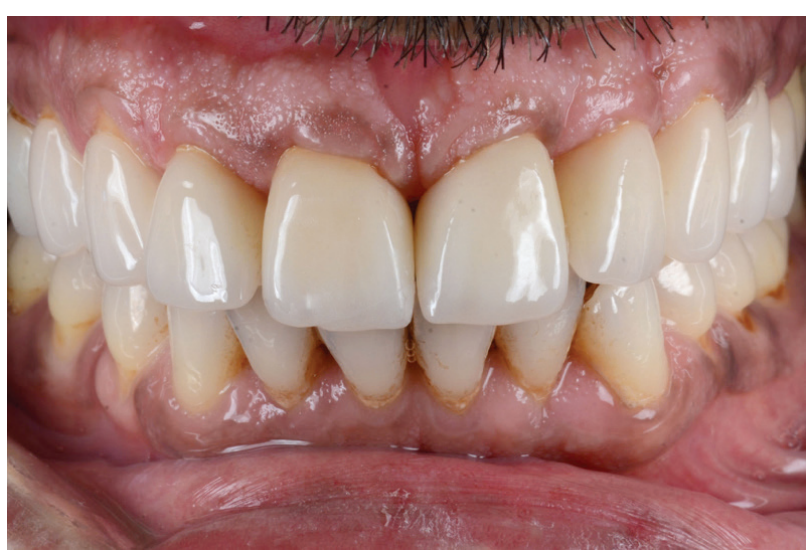

Figure 14 - Intraoral frontal view of bonded porcelain laminate veneer. 


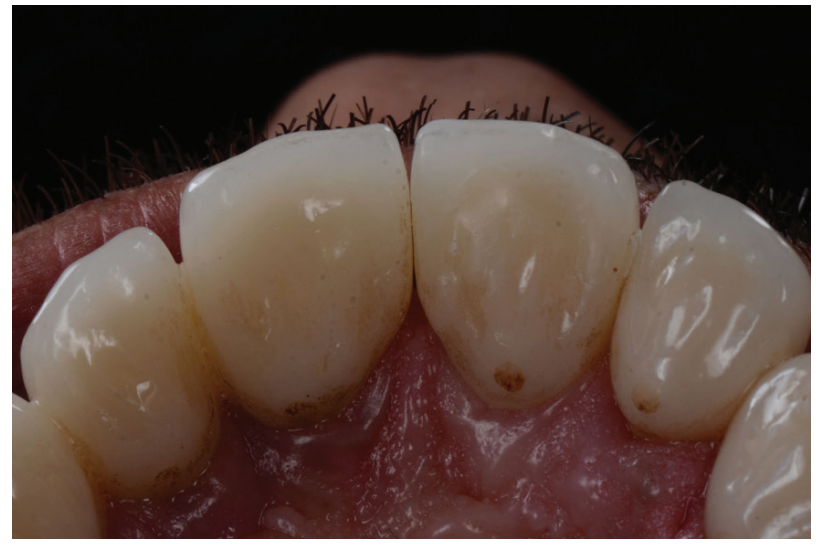

Figure 15 - Palatinal view of bonding area.

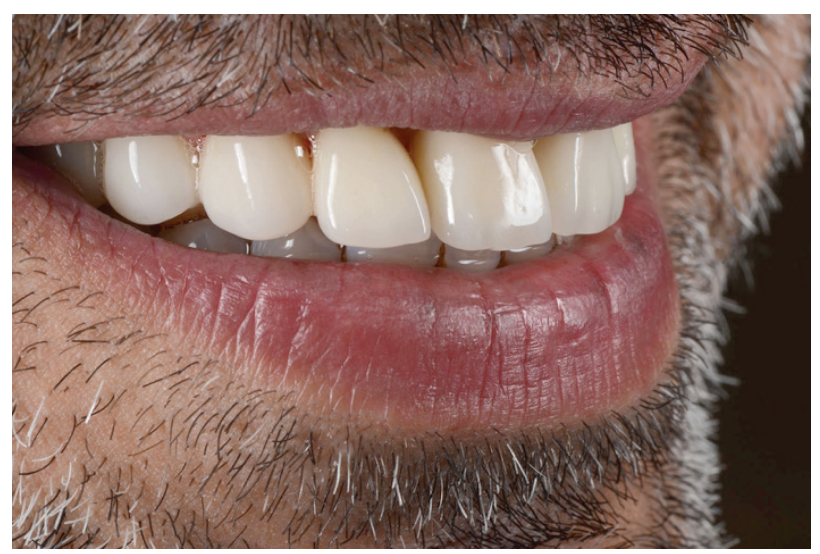

Figure 16 - Right lateral view of bonded porcelain laminate veneer.

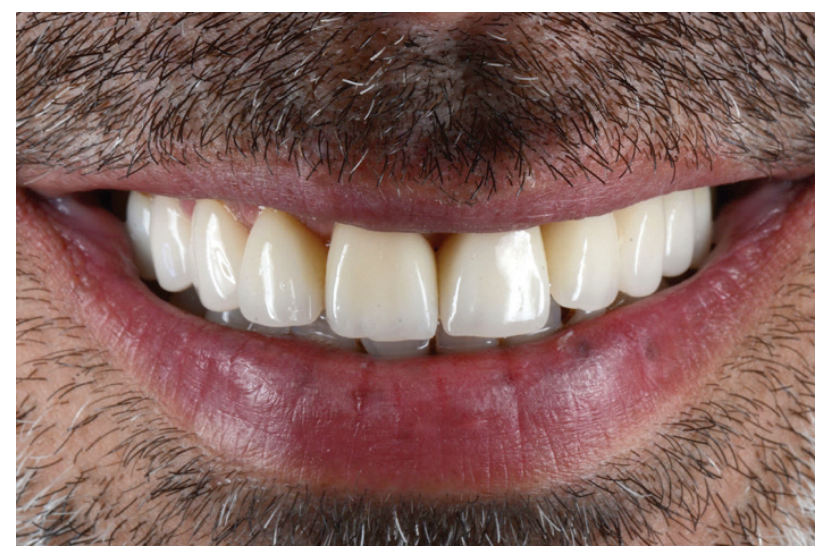

Figure 17 - Frontal view of bonded porcelain laminate veneer.

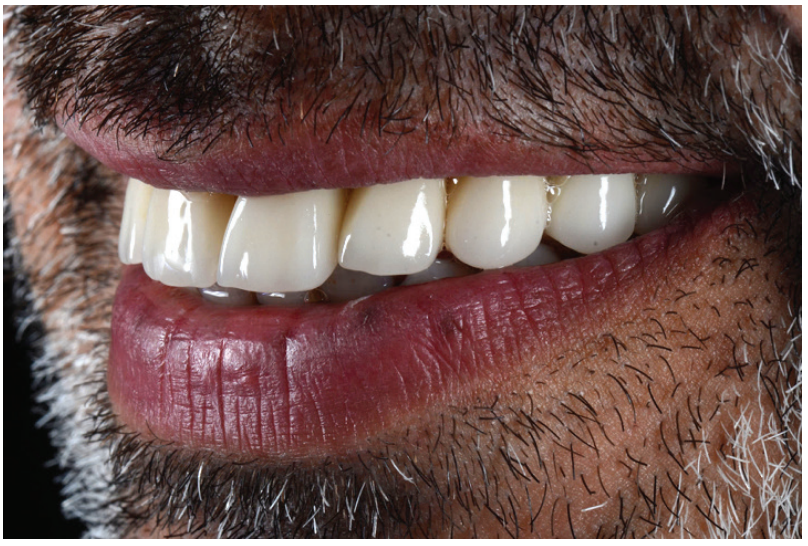

Figure 18 - Left lateral view of bonded porcelain laminate veneer.

\section{CONCLUSION}

This technique allows to clinicians to repair the partial fractured laminate veneer without renewing the laminate veneer.

\section{REFERENCES}

1. D'Arcangelo C, De Angelis F, Vadini M, D'Amario M. Clinical evaluation on porcelain laminate veneers bonded with light-cured composite: results up to 7 years. Clin Oral Investig. 2012 Aug;16(4):1071-9. doi: 10.1007/s00784011-0593-0. Epub 2011 Jul 20.

2. Layton DM, Clarke M, Walton TR. A systematic review and meta-analysis of the survival of feldspathic porcelain veneers over 5 and 10 years. Int $J$ Prosthodont. Nov-Dec 2012;25(6):590-603.

3. Morimoto S, Albanesi RB, Sesma N, Agra CM, Braga MM. Main Clinical Outcomes of Feldspathic Porcelain and Glass-Ceramic Laminate Veneers: A Systematic Review and Meta-Analysis of Survival and Complication Rates. Int J Prosthodont. 2016;29(1):38-49. doi:10.11607/ijp.4315

4. Arif R, Dennison JB, Garcia D, Yaman P. Retrospective evaluation of the clinical performance and longevity of porcelain laminate veneers 7 to 14 years after cementation. J Prosthet Dent. 2019;122(1):31-37. doi:10.1016/j. prosdent.2018.09.007

5. Kang SH, Chang J, Son HH. Flexural strength and microstructure of two lithium disilicate glass ceramics for CAD/CAM restoration in the dental clinic. Restor Dent Endod. 2013;38(3):134-140. doi:10.5395/ rde.2013.38.3.134

6. Mohsen C. Corrosion effect on the flexural strength \& micro-hardness of ips e-max ceramics. Open J Stomatol. 2011;1(02). doi: 10.4236/ ojst.2011.12006

7. Della Bona A, Mecholsky JJ Jr, Anusavice KJ. Fracture behavior of lithia disilicate- and leucite-based ceramics. Dent Mater. 2004;20(10):956-962. doi:10.1016/j.dental.2004.02.004

8. Srichumpong T, Phokhinchatchanan P, Thongpun N, Chaysuwan D, Suputtamongkol K. Fracture toughness of experimental mica-based glass-ceramics and four commercial glass-ceramics restorative dental materials. Dent Mater J. 2019;38(3):378-387. doi:10.4012/dmj.2018-077 
9. Guess PC, Schultheis S, Bonfante EA, Coelho PG, Ferencz JL, Silva NR All-ceramic systems: laboratory and clinical performance. Dent Clin North Am. 2011;55(2):333-ix. doi:10.1016/j.cden.2011.01.005

10. Höland W, Rheinberger V, Apel E, et al. Clinical applications of glassceramics in dentistry. J Mater Sci Mater Med. 2006;17(11):1037-1042. doi:10.1007/s10856-006-0441-y

11. Özcan M, Al-Haj Husain N, Maziero Volpato CA. Verblendungsfrakturdirekte und indirekte Reparaturmethoden. Quintessenz. 2018;69(6):650-7.

12. Gurel G, Sesma N, Calamita MA, Coachman C, Morimoto S. Influence of enamel preservation on failure rates of porcelain laminate veneers. Int $J$ Periodontics Restorative Dent. 2013;33(1):31-39. doi:10.11607/prd.1488

13. Beier US, Kapferer I, Burtscher D, Dumfahrt H. Clinical performance of porcelain laminate veneers for up to 20 years. Int J Prosthodont. 2012;25(1):79-85.

14. Fradeani M, Redemagni M, Corrado M. Porcelain laminate veneers: 6 - to 12-year clinical evaluation--a retrospective study. Int J Periodontics Restorative Dent. 2005;25(1):9-17.

15. Gresnigt MM, Kalk W, Özcan M. Clinical longevity of ceramic laminate veneers bonded to teeth with and without existing composite restorations up to 40 months. Clin Oral Investig. 2013;17(3):823-832. doi:10.1007/ s00784-012-0790-5
16. Smales RJ, Etemadi S. Long-term survival of porcelain laminate veneers using two preparation designs: a retrospective study. Int J Prosthodont. 2004;17(3):323-326.

17. Rinke S, Lange K, Ziebolz D. Retrospective study of extensive heat-pressed ceramic veneers after 36 months. J Esthet Restor Dent. 2013;25(1):42-52. doi:10.1111/jerd.12000

18. Setcos JC, Khosravi R, Wilson NH, Shen C, Yang M, Mjör IA. Repair or replacement of amalgam restorations: decisions at a USA and a UK dental school. Oper Dent. 2004;29(4):392-397.

19. Hickel R, Roulet JF, Bayne S, Heintze SD, Mjor IA, Peters M, et al. Recommendations for conducting controlled clinical studies of dental restorative materials. Science Committee Project 2/98--FDI World Dental Federation study design (PartI) and criteria for evaluation (Part II) of direct and indirect restorations including onlays and partial crowns. J Adhes Dent. 2007;9 Suppl 1:121-47.

20. Heintze SD, Rousson V. Survival of zirconia- and metal-supported fixed dental prostheses: a systematic review. Int J Prosthodont. 2010;23(6):493502.

21. Hickel R, Brüshaver K, llie N. Repair of restorations--criteria for decision making and clinical recommendations. Dent Mater. 2013;29(1):28-50. doi:10.1016/j.dental.2012.07.006

22. Loomans B, Özcan M. Intraoral Repair of Direct and Indirect Restorations: Procedures and Guidelines. Oper Dent. 2016;41(S7):S68-S78. doi:10.2341/15-269-LIT

\section{Assistant Prof. Halenur Bilir \\ (Corresponding address)}

Department of Prosthodontics, Faculty of Dentistry,

Istanbul Medeniyet University, Istanbul, Turkey,

Fatih Mahallesi 34956 Orhanli Tuzla/Istanbul

Date submitted: 2020 Jan 08

E-mail: halenurbilir@gmail.com 